\section{STAPHYLOCOCCUS AUREUS EM LEITE CRU. I. CONTAGEM, VERIFICAÇAOO DA ENTEROTOXIGENICIDADE E FAGOTIPAGEM DAS CEPAS ISOLADAS}

WANDERLEY PEREIRA DE ARAUJO Professor Doutor Faculdade de Medicina Veterinária e Zootecnia da USP

SEBASTINO TIMO IARIA Professor Titular Instituto de Ciencias Biamédicas da USP

GIL VIANNA PAIM

Professor Doutor Faculdade de Saúde Pública da USP

CARLOS SOLE-VERNIN

Professor Titular Faculdade de Medicina de

Ribeirāo Preto-USP

ARAUJO, H.P.; IARIA, S.T.; PAIM, G.V.; SOlE-VERNIN, C. Staphylocaccus aureus em leite cru. I. Contagem, verificaçāo de enterotoxigenicidade e fagotipagen das cepas isoladas. Rev. Fac. Med. Vet. Zootec. Univ. S. Pauto, $26(2): 187 \cdot 198,1989$

RESUMO: foram analisadas 100 amostras de leite cru, obtidas na plataforma de recepção da Usina de Pasteurização do Centro intraunidade de zootecnia e Indústrias Pecuárias (CIZIP) da faculdade de Medicina Veterinária e Zootecnia da Universidade de São Paulo, localizado no Municipio de Pirassununga, SP. A partir de cada amostra realizou-se a contagem de $S$. aureus, em ágar Baird-Parker $37{ }^{\circ} \mathrm{C}$ por $24-48$ horas, sendo as cepas isoladas identificadas atraves da verificação microscópica da morfologia e das provas de produçāo de catalase, de fermentação/oxidação de glicose e da produça de coagulase e termonuclease. Das amostras analisadas, 50 revelaran-se positivas para S. aureus, con contagens que variaram de 30 a $110.000 / \mathrm{ml}$ de leite. Das anostras positivas foran isoladas 201 cepas, as quais foram submetidas à verificaçāo da capacidade pradutora de enterotoxina estafilocócica, empregando-se um métado de cultura en saco de celofane. Para a constatação da presença de enterotoxina nos extratos obtidos, usou-se o processo do depla imunodifusão en gel, en laminas. Do total de cepas exearinado, apenas una, isolada de uma mostra cam $860 \mathrm{~S}$. aureus por $\mathrm{ml}$ de leite, mostrou-se produtora de enterotoxina do tipo B. A fagotipagem esta cepa foi lisada unicanente pelo fago 53, pertencente ao
Grupo III do Conjunto Básico Internacional Humano e ao Grupo III do Conjunto Básico Bovino.

UNITERMOS: Staphylococcus aureus ; Le ite, microbiologia

\section{INTRODUÇAO}

o leite, alimento rico em nutrientes, constitui-se em um excelente meio de cultura para microrganismos, os quais podem ocasionar alteraçōes do produto ou risco aos seus consumidores. Durante e após a ordenha o leite passível de ser contaminado com microrganismos provenientes da ordenhadeira mecánica, do ar, da água utilizada na limpeza de utensflios, como baldes e latões e, por outro lado, os animais doentes ou portadores, Dodem veicular ao leite bactérias patogénicas (COMITE MIXTO FAO/OMS DE EXPERTOS EN HIGIENE DE LA LECHE ${ }^{14}$, 1971).

Dentre as bactérias que se podem encontrar no leite destaque-se o Staphylococcus aureus, microrganismo capaz de provocar doenças no homem e nos animais e que, através dos alimentos, pode ser responsabilizado por casos de intoxicação alimentar. A contaminação de utensílios, equipomentos e alimentos por $S$. aureus pode ocorrer a partir de ordenhadores e outros manipuladores infectados (HOOBS \& GILBERT 32,1978 ) e, também, de animais (MORRISON et ali ${ }^{41}, 1961$ ).

Diversos pesquisadores tèm evidenciado a presença de $S$. aureus no leite cru ou pasteurizado e/ou seus derivados (FERMANDEZ 22,1966 ; GHOSH \& LAXMINARAYANA 26 , 1972; GHOSH \& LAXMINARAYANA 27, 1974; WILSON 58, 1977; AHMED et alii 1, 1978; GOMEZ et alii 30, 1979; CABRAL et al i $\mathrm{i}^{10}, 1983$ ).

De forma geral, estando presente em alimentos, $O S$. aureus pode multiplicar-se e atingir números elevados. Entretanto, deve-se considerar que 0 maior crescimento dessa bactéria no alimento ocorre quando $\mathrm{O} \mathrm{pH}$ estiver na faixa de 7,0 a 7,5 (BAIRD-PARKER ', 1974), a atividade água (an) entre 0,980 e 0,995 (JAY $35^{\circ}, 1973$ ) e a temperatura entre 30 e $37{ }_{C}$ (BAIRD-PARKER 7 1974). Saliente-se que o leite pode apresentar-se com $\mathrm{PH}$ de 6,8 a 7,0 (CORLETT \& BRONN 15,1980 ) e com aw de 0,980 (TROLLER \& CHRISTIAN 55,1978 ).

por outro lado, FRAZIER \& WESTHOFF 23 (1978) destacam que pode ocorrer produçāo de enterotoxina na faixa otime de 21 a $36{ }^{\circ} \mathrm{C}$. Porém referem que quanto mais favorável for o alimento para multiplicaçāo dessa bactéria, mais amplas são as faixas de temperatura e pH que permitem o seu crescimento. E importante considerar que, em nosso meio, o leite após a ordenha, e frequentemente mantido em temperatura ambiente $e$, 
portanto, en condiçס̄es não adequadas para a sua conservaçzo.

Diante disto, levando em conta as características acima referidas, aliades disponibilidade de nutrientes - temperatura, o leite permite a multiplicação de $S$. aureus, que pode atingir números elevados $e$, se for enterotoxigènico, poderá, durante o seu crescimento, produzir enterotoxina estafilocócica.

A intoxicaça alimentar estafilocócica ocorre pela ingest 60 de alimentos contendo enterotoxina produzida por cepas de Staphylococcus coagulase positivas, embora nem todas as cepas sejam enterotoxigénicas (EVANS 20, 1948 e EVANS et alii 21,1950 ). Os sintomas mais freqüentes, observados nessa intoxicação, ocorrem 1 a 6 horas após a ingestão do alimento e se revelam por sialorréia, náusea, vónito, diarréia e, commente, hipotermia (DACK ${ }^{16}, 1964$ e FRAZIER \& WESTHOFF 23 , 1978). E uma doença de alta morbidade, porén de baixa letalidade (GILBERT 28 , 1974) e os individuos acometidos geralmente se recuperam num períado de 1 a 3 dias (DACK ${ }^{16}$, 1964).

Com relação a enterotoxina estafilocócica, atualmente são conhecidos 6 tipos sorológicos denominados A, B, C, D, E e F. Os processos de pasteurização e de desidratação destroem a maioria ou todos os estafilococos, mas nāo inativam a enterotoxina produzida (INTERNATIONAL COMISSION ON MICROBIOLOGICAL SPECIFICATIONS FOR FOOOS 34 , 1978), já tendo sido relatados alguns surtos de intoxicação alimentar estafilocócica relacionados i ingestão de leite em pó reconstituido que não continha estafilococos viáveis (ANDERSON \& STONE ?, 1955 e ARMIJO et alii 4, 1957).

Em paises cono Espanta (FERMANDEZ 22, 1966), Estados unidos (CASMuM et alii 12, 1967), India (GHOSH \& LAXMINARAYANA 26, 1972 E RUMAR \& GUPTA 37, 1983), Inglaterra (HIENEKE 56,1974 ), Egito (AHMED et alii , 1978) Japōo (KATO \& KUME 36 , 1980) e Hungria (LOMBAI et alii 39, 1980), em anostra de leite e seus derivados, foi demonstrada a presença, em percentagens variáveis, de cepas S. aureus, produtoras dos diferentes tipos de enterotoxina estafilococica.

No Brasil, alguns pesquisadores tèm evidenciado a ocorrência de cepas de $S$. aureus produtoras de enterotoxina, isoladas de alimentos como macarrāo (DELAzARI \& LEITIO 18, 1976), linguica fresca (RUdGe 47 , 1980), doces cremosos (IARIA 33 1981), produtos cárneos embutidos (HIROOKA \& MLLER 31, 1982), queijo coalho (CABRAL et ali 10,1983 ), carne moida (CERQUEIRA-CAMPOS - IARIa ${ }^{13}$, 1983). A partir de leite de vacas com mastite evidenciou-se, também, a enterotoxigenicidade das cepas isolodes (SCMOCKEN-I TURRINO et ali 48 1986; FURLANETIO et alii 24, 1987; NADER FILHO et alii 42, 1988).

Em investigaçōes epideniológicas de surtos de intoxicaç̄o alimentar estufilocócicas HILLIAMS et alii 57 , 1953 referen a utilização da fagotipagem das cepas de
$S$. aureus isoladas dos alimentos envolvidos, tentando-se relacionar o fagótipo com a produção de enterotoxina.

Para tanto, em 1974, estabeleceu-se um conjunto Básico Internacional de bacteriófagos, ao qual as cepas de estafilococos devem ser submetidas (SOLE-VERNIN 52 , 1976). Embora esse Conjunto de bacterífagos, utilizado para fagotipagem de cepas de origem humana, possa lisar cepas isoladas de bovinos (BLAIR \& HILLIAMS 9 , 1961), alguns autores sugerem, para cepas isoladas de leite, a utilização de um conjunto de bacteriófagos obtidos de estafilococos de origem bovina (SETO \& HILSON 49, 1958; NAKAGAWA 43, 1960; DAVIDSON 17, 1961; MARKHAM \& MARKHAM 40, 1966) a fim de se aumentar o indice de tipificação desses microrganismos.

Na Inglaterra sIMKOVICOVA \& GILBERT 51 (1971) e GILBERT \& HIENEKE 29 (1973) verificaram que a maioria das cepas de $S$. aureus, isoladas de alimentos envolvidos em surtos de intoxicação alimentar, eram sensf́veis a fagos dos Grupos 111 ou 1/III. ANGELOTTI 3 (1969) e GILBERT 28 (1974) salientam, entretanto, que a produção de enterotoxina não pode ser prevista, simplesmente, a partir dos resultados da fagotipagem.

Do exposto pode-se depreender que, en nosso meio, 6 necessária a realização de novas investigaçōes sobre a presença e quantidade de $S$. aureus no leite cru, ben como, a verificação da capacidade enterotoxigenica das cepas isoladas desse alimento e da sensibilidade a bacteriófagos dos Conjuntos Básicos Humano e Bovino.

São objetivos da presente investigação:

1-Constatar a presença e o numero de Staphylococcus aureus em anostras de leite cru.

2-Verificar a capacidade enterotoxigènica das cepas de $S$. aureus isoladas.

3-Verificar o comportamento das cepas de S. aureus isolados frente às provas de fagotipagen.

\section{MATERLAL E MÉTODO}

As amostras de leite foram colhidas na plataforma da usina de pesteurização do centro Intraunidade de Zootecnia e Indústrias Pecuárias (CIZIP) da Faculdade de Medicina Veterinária e Zootecnia da USP, localizado em Pirassununga, São Paulo.

Em tubos esterelizados, foram colhidas 100 amostras de leite de latōes provenientes das 5 limhas de leite existentes, tomando-se o cuidado de colher, no mínimo, una amostra de cada propriedade.

A partir de cada amostra foi realizada a contagen de S. aureus, verificação do comportanento das cepas 
isoladas, frente a provas bioquimicas e de fagotipagem, e tambér, quanto a capacidade enterotoxigénica.

Para cada amostra prepararam-se diluicōes decimais en solução de água fosfatada esterilizada e com pH 7,2, semeando-se $0,2 \mathrm{ml}$ da amostra de leite e suas diluiços em placas de Petri contendo bgar Baird-Parker. As placas eram incubadas $37^{\circ} \mathrm{C}$ por 24 ou 48 horas (INTERNATIONAL COMISSION ON MICROBIOLOGICAL SPECIFICATION FOR FOOOS 34 , 1978), rea(izando-se, a seguir, a contagem do numero de colônias de cor negra, brilhantes, com zona de precipitação ao redor e circundadas por halo claro (BAIRD-PARKER ${ }^{5}$, 1962), nas placas con 30 a 300 colónias. Multiplicando-se o número de colónias por 5 e pelo fator de diluiçào obtinha-se o nimero presuntivo de $S$. aureus por mililitro de leite.

Efetuava-se, então, 0 isolamento de 1 a 5 colónias por amostra, a partir de placa de contagem, semeando-se em tubos de ágar simples inclinado, incubados a $37^{\circ} \mathrm{C}$, por 24 horas. Comprovando-se a presenca de cultura pura de cocos Gram-positivos, agrupados em forma de cachos, realizava-se a identificação bioqufmica das cepas isoladas através das provas de catalase, oxidaçãofermentação da glicose, coagulase em plasma de coelho e da termonuclease (BAIRD-PARKER 6, 1966; SUBCOMMITTEE TAXONOAY OF STAPHILOCOCCI AND HICROCOCCI 53, 1965; LACHICA et alii 38, 1971; ZELANTE 59, 1974). Após identificaçào bioquímica, o resultado da contagem presuntiva era confirmado ou corrigido.

A fagotipagen das cepas de $S$. aureus foi realizada na Secão de Fagotipagen do Departamento de Parasitologia, Microbiolagia e Imnologia da Faculdade de Medicina de Ribeirāo Preto da USP, por gentileza do Professor Dr. Carlos Sole-vernin. Para tanto, utilizou-se o Conjunto Básico Internacional para cepas de origem bovina. Para composição desse conjunto, 7 dos 16 fagos, utilizados exclusivamente para fagotipagem de cepas bovinas, foram cedidos gentilmente pelo Laboratório Veterinário Central do Ministério da Agricultura, Pesca e Alimento da inglaterra, e os demais fagos pertenciam à coleção de bacteriófagos de Ribeirāo Preto.

os dois conjuntos de bacteriófagos utilizados para fagotipagem das 201 cepas de $S$. aureur isolades de leite estão relacionados, a seguir:

CONJUNTO BASICO INTERMACIONAL DE BACTERIOFAGOS PARA FAGOTIPAGEM DE CEPAS DE S. AUREL'S DE ORIGEM HUMANA.

Grupo Bactenófagos

$$
\begin{array}{ll}
1 & 29,52,521,79,80 \\
11 & 3 A, 3 C, 55,71 \\
111 & 6,42 E, 47,53,54,75, \\
& 77,834,84,85
\end{array}
$$$$
\text { Nāo }
$$

Classificados $81,94,95,96$

Rev. Fac. Med. Vet Zootac. Univ. S. Paulo, 26(2):187-198, 1989.
CONJUNTO BASICO INTERMACIONAL DE BACTERIOFAGOS PARA FAGOIIPAGEM DE CEPAS DE S. AUREUS DE ORIGEM BOVINA.

$\begin{array}{ll}\text { Grupo } & \text { Bacueriófagos } \\ \text { I } & 29,524 \\ \text { II } & 3 A, 116 \\ \text { III } & 6,42 E, 53,75,84 \\ \text { IV } & 420,102,107,117 \\ \text { Miscelánea } & 78,118,119\end{array}$

Nas provas de fagotipagem empregou-se a técnica recomendada por BLAIR \& WILLIAMS 9 (1961), submetendo-se, inicialmente, as cepas aos diferentes fagos dos 2 Conjuntos na concentração de IXRTD (Routine Test Diluition) e, quando nào reagentes, submetidos a $100 \times R$ To.

- fagótipo de cada cepa era constituldo levando-se em consideracão, inicialmente, o resultado da fagotipagem a IXRTO para os dois conjuntos de bacteribfagos ou, caso não houvesse lise nessa diluição, a 100xRTo.

Quanto à verificaçào da produçāo de enterotoxina a partir das cepas de $S$. aureus isoladas, foram utilizadas as enterotoxinas e antienterotoxinas padrōes $A, B, C, D$, E, preparadas pelo "food Research Institute of Wisconsin University", Estados Unidos, e gentilmente fornecidas pelo Professor Merlin S. Bergdoll.

Pars a produção de enterotoxina pelas cepas de $S$. aureus isoladas empregou-se a técnica de DONNELY et ali i 19 (1967), modificada por sImKOVICOVA \& GILBERT 5 \% (1971), e que consiste na cultura das cepas de S. aureus ao redor de un saco de celofane, contendo caldo infusão de cérebro e coraçào em concentração dupla, colocado no interior de um Erlemmeyer. Após un períado de incubação de 48 horas à $37{ }^{\circ} \mathrm{C}$, a suspensào bacteriana era centrifugada por 45 minutos a 4.200 rpm em centrífuga refrigerada, utilizando-se 0 sobrenadante, que constituia o extrato, para a pesquisa de enterotoxina estafilococica.

Para se verificar a presença de enterotoxina nos extratos obtidos utilizou-se a técnica de dupla imunodifusào, empregada por SILES VILLARROEL 50 (1972), em laminas de microscopia. Para tanto as làminas eram cobertas com 2 camadas de ágar a $1 \%$ e, após solidificação do ágar, eram feitas 5 perfuraçōes, uma central e quatro periféricas, sendo cada conjunto de 5 orificios correspondente à pesquisa de un tipo de enterotoxina.

Na pesquisa de enterotoxina, os 5 orificios centrais eram preenchidos, respectivamente, com as soluçöes padröes de antienterotoxina estafilocócica $A, B, C, D$ e E. Nos orifficios superior direito e inferior esquerdo colocava-se as soluçöes padrōes de enterotoxina A, B, C, D e E, respectivamente, e os orificios superior esquerdo e inferior direito dos 5 conjuntos eram preenchidos com o 
extrato, no qual se estava pesquisando a presenca de enterotoxina.

Após un perfodo de incubaçäo de 24 horas a $37^{\circ} \mathrm{C}$, efetuava-se una primeira leitura das laminas. A seguir, após secagem do ágar em estufa a $60^{\circ} C_{C}$ as láminas eram coradas com una solução de Amido Schwars 10 B (SILES VILLARROEL 50, 1972). Realizava-se, então, uma segunda leitura para elucidaçăo de reaçōes duvidosas constatadas na primeira leitura. Considerava-se reação positiva para um determinado tipo de enterotoxina, quando se formava una linha contínua de precipitação ao redor do oriff́cio central.

\section{RESULTADOS E DISCUSSAO}

Na Tab. 1 encontra-se a distribuicão das amostras de leite das 5 linhas existentes em Pirassununga segundo a positividade para $S$. aureus.

Verifica-se na Tab. I que das 100 amostras de leite examinadas, 50\% apresentaram-se positivas para $S$. aureus, valor que poderia ser maior se tivessem sido empregadas técnicas de enriquecimento, mas, mesmo assim, a taxa de positividade pode ser considerada elevada. Observa-se, ainda, que das 5 linhas de leite, a que forneceu amostras desse produto com menor positividade para $S$. aureus foi a linha $a \quad(25,0 \%)$. Entretanto, tal linha 6 representada por apenas una propriedade leiteira de boa qualidade e de alta produção, onde os animais são ordenhados mecanicamente. Com relação a limha $b$, a positividade para $S$. aureus foi elevada, porém essa linha é, também, representada por apenas una propriedade de baixa produção leiteira, e portanto, o resultado deve ser considerado con reservas.

Por outro lado, as linhas $c, d$ e $e$, cada una com 20, 17 e 14 propriedades, que através de ordenha manual, produziram no dia da colheita 1332, 1753 e 1906 litros de leite, respectivamente, apresentaram positividade para $S$. aureus de $57,1 \%, 48,4 \%$ e 55,9\%, respectivamente, valores tambén considerados al tos.

Porém, HILSON 58 (1977), analisando amostras de leite cru obtidas em duas Companhias de leite da região de Paraibuna, São Paulo, constatou positividade para $S$. aureus de $76,4 x$ e $88,7 x$, respectivanente, estas, portanto, muito mais elevadas do que as observadas no presente estudo.

Na Tab. 2, estäo distribuídas as 53 propriedades das 5 limas, das quais forem obtidas as amostras de leite, segundo a positividade para $S$. aureus.

Observa-se na Tab. 2 que un número elevado de propriedades leiteiras, ou seja, $36(67,9 \%)$ revelaram-se con amostras de leite positivas para $S$. aureus.

Considerando-se apenas as linhas $c, d e e$, pois as linhas $a$ e $b$ eram representadas por apenas una propriedade leiteira cada uma, verifica-se que 12 $(60,0 \%), 11(64,7 x)$ e $11(78,6 x)$ propriedades respectivamente, forneceram amostras de leite positivas para S. aureus, revelando-se, portanto, un número elevado de propriedades em que esse produto apresentava-se contaminado por essa bactérja.

Esses fatos demonstram que a contaminação do leite, por cepas de $S$. aureus, provenientes de animais, de pessoas que manipulam o produto, de utensllios utilizados, ou ainda do próprio ambiente, é elevada. Isto sugere que as medidas higiénico-sanitárias devem ser aplicadas com mais rigor, a fim de se evitar um elevado grau de contaminação por S. aureus e sua multiplicaçāo, para que se possa obter un produto de melhor qualidade.

$\mathrm{Na}$ Tab. 3 estão distribuldas, em $7 \mathrm{classes,} \mathrm{as} 100$ amostras de leite, segundo o número de $S$. aureus por mililitro e a positividade para cepas produtoras de enterotoxina estafilocócica.

Das 100 amostras examinadas 50 (50,0\%) apresentaram contagens de $S$. aureus, que variaram entre 5 a $5 \times 10$ e $10^{5}$ e mais, (30 a 110.000), valores esses relativamente baixos, quando comparados com os obtidos por WILSON 58 (1977) en São Paulo. Esse autor observou que 258 e 149 amostras de leite cru colhidas, respectivamente, em duas usinas da regiāo de Paraibuna, SP, apresentavam contagens médias de $S$. aureus, de 1.878 .000 e 780.000 por ml, respect ivamente.

E importante salientar que das 50 amostras positivas para S. aureus, apenas una continha $10^{5}$ ou mais dessa bactéria, valor esse tido como limite, a partir do qual o alimento pode causar intoxicação alimentar estafilocócica. Para isto, obviamente, deve ocorrer a multiplicação de $S$. aureus produtor de enterotoxina no al imento.

A este respeito, PETERSON et alii 45 (1962) consideram que para causar intoxicaçăo alimentar, o alimento deve contar de $10^{6}$ a $10^{9}$ S. aureus por grama ou mililitro. GILBERT 28 (1974) refere 53 surtos dessa doenca, cujos alimentos associados, revelaram-se com contagens de $S$. aurews de $1,2 \times 10^{5}$ a $10^{9}$ ou mais por grama.

A contagem alta de $S$. aureus enteroxigènico no alimento $e$ importante porque, para causar intoxicação alimentar deve ocorrer a produção de enterotoxina $\mathrm{am}$ quantidades capazes de promover o surgimento de sintomas de intoxicação. CASMAN \& BENNETt 11 (1965) e ANGELOTTI 3 (1969) consideram que essas quantidades devam ser de 1 a 4 ug e 1 a 5 ug, respectivamente. Porém, BERGDOLL 8 (1973) ressalta que a ingestão de quantidades de enterotoxina até inferiores a 1 ug podem determinar 0 surgimento de sintomas.

Com relação ao leite, alguns pesquisadores em outros paises, demonstraram percentagens variáveis de isolamento de cepas de $S$. aureus, produtoras de enterotoxina. 
Na Espanha, em amostras de leite cru, FERNANDEz 22 (1966) verificou que de 18 cepas de estafilococos coagulase-positivos, 5 eram produtoras de enterotoxina estafilocócica. Outros pesquisadores, como CASMAN et alii 12 (1967) nos Estados Unidos, GHOSH \& LAXMINARAYANA 26 (1972) e KUMAR \& GUPTA 37 (1983) na India, WIENEKE 56 (1974) na Inglaterra, evidenciaram cepas de $S$. aureus enterotoxigenicas isoladas a partir de leite cru, em percentagens de $10,0 \%, 7,0 \%, 23,3 \%$ e $6,0 \%$, respectivamente. Nessas pesquisas as enterotoxinas estafilocócicas produzidas, demonstradas pelos autores citados, foram dos tipos A, B, C, D e da associação dos tipos $A B, B D$ e $C D$.

Por outro lado, na Hungria, LOMBAl et alii 39 (1980), em 101 cepas de $S$. aureus isoladas de leite, salientam que nenhuma cepa isolada de vacas assintomáticas para mastite, revelou-se produtora de enterotoxina, ao passo que 4 cepas, isoladas de leite de vacas com mastite, produziram enterotoxina do tipo $C$.

com relação a cepas de $S$. aureus enterotoxigènicas, isoladas a partir de leite de vacas com mastite, as percentagens evidenciadas por diferentes autores, como CASMAN et alii ${ }^{12}$ (1967); OLSON et al i ${ }^{44}$ (1970); GARCIA et alii 25 (1980); TAKESHIGE et alii ${ }^{54}$ (1983), foram de $2,0 \%, 14,6 \%, 7,0 \%$ e $33,3 \%$, respectivamente. No Brasil, SCHOCKEN-ITURRINO et alii $48(1986)_{\text {j }}$ FURLANETTO et ali 24 (1987); NADER flLHO et alii $4 \hat{2}$ (1988) verificaram percentagens de $15,79 \%, 8,0 \%$ e $1,3 \%$, respectivamente, para cepas isoladas de vacas com mastite.

No Japão, KaTo \& KUME ${ }^{36}$ (1980) observaram que de 1056 cepas de $S$. aureus, isoladas de vacas que reagiram positivamente ao "California Mastitis Test" (CMT), 363 (34,3\%) produziram enterotoxina dos tipos $A, B, C$ ou $D$, sendo a maioria, ou seja, $197(54,3 \%)$ produtoras do tipo C, isoladamente ou em associação com outros tipos.

Na presente investigação, analisando-se a Tab. 3 observa-se que apenas de uma $(1,0 \%)$ amostra de leite obteve-se $O$ isolamento de $S$. aureus produtor de enterotoxina do tipo B, proporção essa inferior às abtidas nos estudos realizados pelos autores referidos. Cumpre salientar que essa amostra continha entre $10^{2}$ e $10^{3}$ S. aureus por $\mathrm{ml}$ de leite e, mais especificamente, $860 / \mathrm{ml}$. Dessa amostra, foram isoladas 5 cepas dessa bacteria, das quais apenas una revelou-se produtora de enterotoxina. Admitindo-se que as 5 cepas isoladas representavam o total de colónias da placa de contagem, dos $860 \mathrm{~S}$. aureus $/ \mathrm{ml}$ de leite, $172 / \mathrm{ml}$ poderiam ser considerados enterotoxigénicos, não se evidenciando, portanto, significado epidemiológico imediato en relaçāo à possibilidade de ocasioner intoxicação alimentar estafi locócica.

Quanto à fagotipagern realizada com o Conjunto Básico Humano, verifica-se pela Iab. 4, que das 201 cepas de $S$. aureus testadas, $68(33,8 \%)$ foram lisadas por fagos do Grupo III e $32(15,94)$ dos Grupos III e NC, em associação, resultados semelhantes aos obtidos por RAMMAN \& BAXI 46 (1983), em amostras de leite de vacas com mastite, na India.

Por autro lado, com relação à fagotipagem efetuada com o Conjunto Básico Bovino, pode-se constatar na tab. 5 que houve predominancia de cepas lisáveis por fagas dos Grupos $111(16,9 \%)$ e IV $(17,4 \%)$ isoladamente e em associação $(12,4 \%)$. Estes resultados concordam com os verificados por GARCIA et alii 25 (1980), em estudo realizado com 57 cepas de $S$. aureus isoladas de leite de vacas com mastite, na Espanha.

No presente estudo, as 68 cepas sensiveis, exclusivamente, a fagos do Grupo 111 e as 32 dos Grupos Ill/NC em associaçāo, pertencentes ao conjunto Básico Internacional Humano, foram isoladas de $31(62,0 \%)$ e 22 $(44,0 \%)$ amostras de leite positivas para $S$. aureus, provenientes de $26(72,2 \%)$ e $20(55,6 \%)$ propriedades, respectivamente ( $T$ ab. 4 ).

De outra parte, as $34(16,9 \%)$ cepas que foram lisadas somente por fagos do Grupo 111 , as $35(17,4 \%)$ unicamente do Grupo IV e as $25(12,4 \%)$ sensiveis a fagos dos Grupos 111 e IV em associação, pertencentes ao Conjunto Básico Internacional Bovino, foram isoladas de $18(36,0 \%), 14(28,0 \%)$ e $15(30,0 \%)$ amostras positivas para S. aureus, oriundas de $17(47,2 \%), 13(36,1 \%)$ e 14 $(38,9 \%)$ propriedades positivas, respectivamente (Tab. 5).

Estes resultados mostram que houve um predomínio de cepas lisáveis por fagos dos Grupos III e III/NC do Conjunto Básico humano e por fagos dos Grupos III, iv e Ill/IV do Conjunto Básico Bovino.

Entretanto, deve ser salientado que $35(17,4 \%)$ cepas isoladas de $19(38,0 \%)$ amostras de leite positivas para $S$. aureus, mostraram-se não tipáveis frente aos fagos do Conjunto Básico Humano (Tab. 4). 0 mesmo ocorreu com relação a $23(11,4 \%)$ cepas isoladas de $13(26,0 \%)$ amostras positivas para aquela bactëria, frente ao Conjunto Básico Bovino ( $T$ ab. 5).

Como já foi referido, das amostras de leite analisadas, isolou-se apenas $1(1,0 \%)$ cepa enterotoxigênica. Tal cepa mostrou-se sensivel ao fago 53. comum aos Grupos III dos Conjuntos Básico Humano e Bovino.

Tendo em vista os resultados obtidos na presente investigação, novos estudos devem ser realizados a respeito, fazendo-se necessária, também, a adoção de medidas higiênico-sanitárias, nem sempre fáceis de serem aplicadas, visando a obtenção de leite com melhor qualidade bacteriológica, a fim de se reduzir, ao máximo, a contaminaçāo desse produto por $S$. aureus.

Tais medidas devem incluir educação sanitária de manipuladores do leite, como ordenhadores e pessoal responsável pelo transporte desse alimento à usina. Devem ser observados cuidados especiais na limpeza dos utensilios utilizados na ordenha e no transporte do leite, bem como, no resfriamento e transporte rápido à 
usina. Também são desejáveis medidas higiênicas relacionadas aos rebanhos leiteiros, a fim de se reduzir - conteminaçäo do leite, tais cono, controle da mastite, limpeza e assepcia do übere e tetas antes da ordenha, evitando-se incluir vacas com mastite, as quais deverão ser ordenhades a parte e tratadas adequadamente.

\section{CONCLUSOES}

De acordo com os resultados obtidos e a discussão desenvolvida no presente estudo, esperamos ter contriburdo com algumas informaçōes de interesse, que poden ser resumidas nas seguintes conclusões:

01-Das amostras de leite cru, obtidas na plataforma de recepção da Usina do Centro Intraunidade de Zootecnia e Indústrias Pecuárias (CIZIP) de Pirassununga, SP, a partir de latões oriundos de 53 propriedades que compuntian as 5 linhas de leite existentes, $50(50,0 \%)$ revelaram-se positivas para $S$. aureus, taxa esta que pode ser considerada alta.

02-Das 53 propriedades, $36(67,9 \%)$ revelaram-se com amostras de leite positivas para $S$. aureus, sendo observada una grande variação do número dessa bactéria, ou seja, de 30 a 110.000 por mililitro.

03-Apenas de una (1,0\%) amostra de leite, contendo $860 \mathrm{~S}$. aureus/ml, isolou-se una cepa enterotoxigènica desta becteria, a quil era produtora de enterotoxina do tipo B. Esta cepa era sensivel somente ao fago 53, dos Conjuntos Básicos Internacionais Humano e Bovino.

04-Um elevado numero de cepas de $S$. aureus isolados, foi lisado tanto por fagos do Conjunto Básico Internacional para cepas de origem humana como do Conjunto Básico Internacional para cepas de origem bovina, não sendo tipáveis $35(17,4 \%)$ e $23(11,4 \%)$ cepas, frente aos dois conjuntos de fagos, respect ivamente.

05-Das cepas estudadas, houve predominância das lisáveis por fagos dos Grupos 111 isoladamente $(33,8 \%)$, e dos Grupos 111/NC en associação $(15,9 \%)$, frente ao Conjunto Básico Humano. Por outro lado, con o Conjunto
Básico Bovino, observou-se maior freqüéncia de cepas sensiveis a fagos dos Grupos III $(16,9 x)$, IV $(17,4 x)$ e III/IV, em associação $(12,4 x)$.
ARAUJO, H.P.; IARIA, S.T.; PAIM, G.V.; SOLE-VERnIN, C. Staphylococcus aureus in row milk. Bacterial counts, enterotoxin production and phage-typing of the isolates. Rev. Fac. Med. Vet. Zootec. Univ. S. Paulo, 26(2):187 198, 1989.

SUMMARY: The presence of $S$. aureus and its enterotoxin was investigated in 100 samples of row milk, collected at the reception platform of a milk pasteurization plant located in Pirassununga, São Paulo, Brazil. All samples were submetted to Baird-Parker agar and positive samples were counted and tested for catalase, fermentation and oxidation of glucose, coagulase in rabbit plasma and for thermonuclease activity. A total of 201 S. aureus isolates were isolated from 50/100 (50.0x) of the samples studied, the counts varied from 30 to 110.000 bacteria per $\mathrm{mt}$ of milk. The enteretoxigenic capacity of the isolates was verified according to the celophane sac culture method and the detection of the enterotoxins $A, B, C, D$ and $E$ was by means of the double gel immunodifusion slide test, using the supernatant fluid extract obtained from the staphylococcal growths. Production of enterotoxin was demonstrated in one strain isolated from a sample that showed a count of 860 bacteria/ml and its enterotoxin belonged to type B. The enterotoxigenic strain was susceptibie to the phage 53 , a phage type common to human and bovine set.

UNITERMS: Staphylococcus aureus; Milk microbiology 
Staphylococcus auseus em leite cru. I. Contagem, verificação da enterotoxigenicidade ...

TABELA 1 - Distribulção das amostras de leite segundo as suas linhas de origem e positividade $(\mathbb{N}$ e \%) para $S$. aureus. Pirassununga, SP, 1981 .

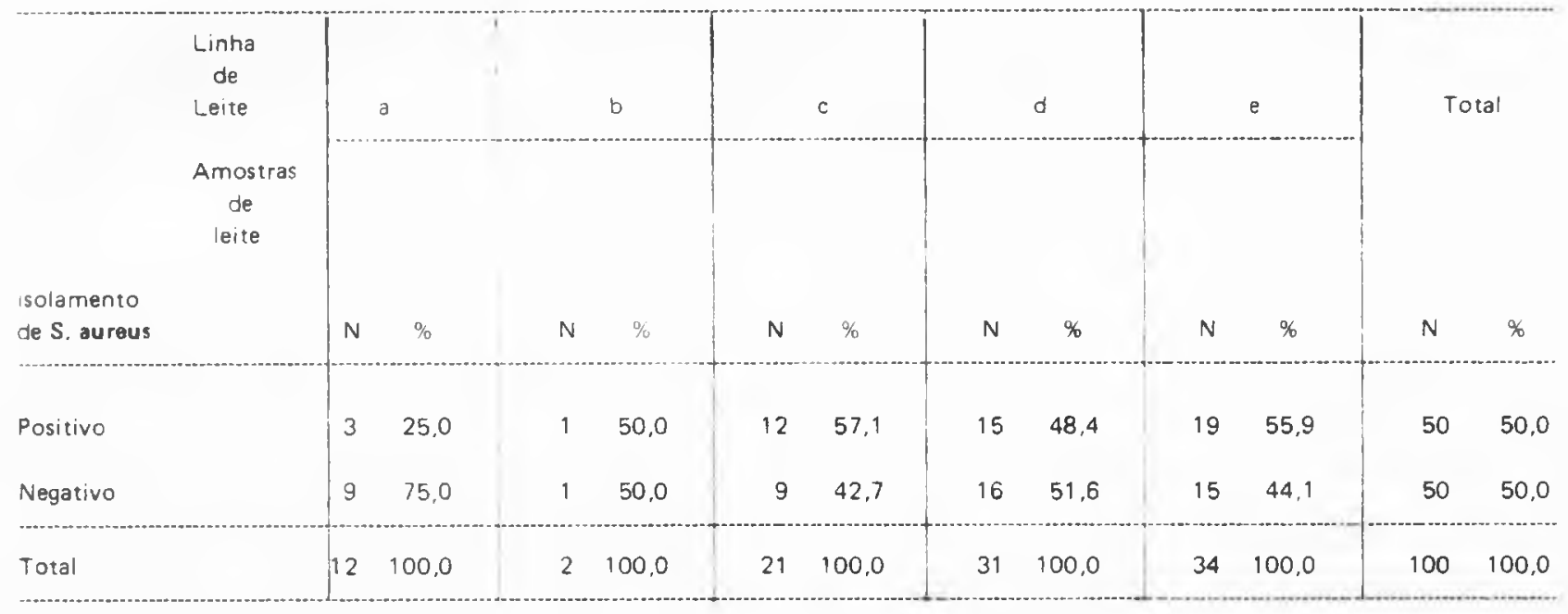

TABELA 2 - Distribuição das propriedades leiteiras segundo a positividade (N e \%) para S. aureus, em amostras de leite examinadas obtidas das diferentes linhas. Pirassunınga, SP. 1981

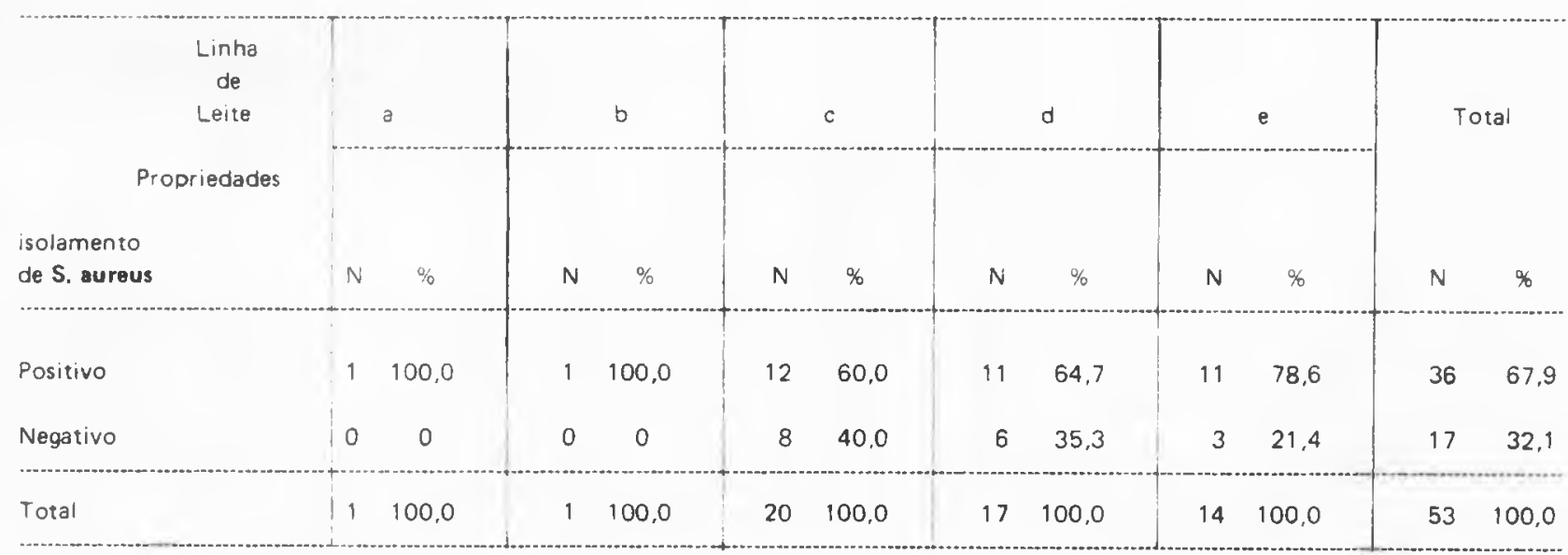


194 ARAUJO, W.P. et alii

Staphvlococcus aureus em leite cru. I. Contagem, verificaçāo da enterotoxigenicidade...

TABELA 3 - Distribuição das 100 amostras de leite segundo o número de $\mathbf{S}$. aureus par mililitro de leite e a positıvidade ( $\mathrm{N}$ e \%) para cepas enterotoxigènicas. Pirassununga, SP, 1981.

\begin{tabular}{|c|c|c|c|c|c|c|c|}
\hline \multicolumn{3}{|c|}{$\begin{array}{l}\text { S. aureus por } \\
\text { mililitro }\end{array}$} & \multicolumn{5}{|c|}{ Amostras de leite } \\
\hline & & & \multicolumn{5}{|c|}{ Com cepas de $\mathbf{S}$. aureus produtoras de enterotoxina } \\
\hline & & & $\mathrm{N}$ & $\%$ & $\mathrm{~N}$ & $\%$ & tipo \\
\hline 0 & -- & 5 & 50 & 50,0 & - & - & - \\
\hline 5 & $\ldots$ & $5 \times 10$ & 1 & 1.0 & - & - & - \\
\hline $5 \times 10$ & --- & $10^{2}$ & 1 & 1,0 & - & - & - \\
\hline $10^{2}$ & --- & $10^{3}$ & 15 & 15,0 & 1 & 1,0 & B \\
\hline $10^{3}$ & -- & $10^{4}$ & 17 & 17.0 & - & - & - \\
\hline $10^{4}$ & --- & $10^{5}$ & 15 & 15.0 & - & - & - \\
\hline \multicolumn{3}{|c|}{$10^{5}$ e mais } & 1 & 1,0 & - & - & - \\
\hline \multicolumn{3}{|c|}{ TOTAL } & 100 & 100,0 & 1 & 1.0 & \\
\hline
\end{tabular}

TABELA 4 - Distribuição das 201 cepas de S. aureus, segundo a fagotıpagem com o Conjunto Básico Internacional Humano e sua relação com as 50 amostras positivas para essa bactéria, obtidas de 36 propriedades leiteiras. Pirassununga, SP, 1981.

\begin{tabular}{|c|c|c|c|c|c|c|}
\hline \multirow[t]{2}{*}{$\begin{array}{l}\text { S. aureus correspondente aos } \\
\text { Grupos de fagos }\end{array}$} & \multicolumn{2}{|c|}{$\begin{array}{l}\text { Cepas de } \\
\text { S. aureus" }\end{array}$} & \multicolumn{2}{|c|}{$\begin{array}{l}\text { Amostras } \\
\text { de leite*" }\end{array}$} & \multicolumn{2}{|c|}{$\begin{array}{l}\text { Propriedades } \\
\text { leiteiras*** }\end{array}$} \\
\hline & $\mathrm{N}$ & $\%$ & $N$ & $\%$ & $N$ & $\%$ \\
\hline I & 5 & 2,5 & 5 & 10.0 & 5 & 13,9 \\
\hline I I & 6 & 3,0 & 2 & 4,0 & 2 & 5.6 \\
\hline 111 & 68 & 33,8 & 31 & 62,0 & 26 & 72.2 \\
\hline NC & 1 & 0.5 & 1 & 2,0 & 1 & 2,8 \\
\hline$|/|||$ & 6 & 3,0 & 3 & 6,0 & 3 & 8,3 \\
\hline$|1 / 1| 1 \mid$ & 10 & 5,0 & 6 & 12,0 & 6 & 16,7 \\
\hline I/NC & 9 & 4,5 & 4 & 8.0 & 4 & 11,1 \\
\hline $11 / N C$ & 32 & 15.9 & 22 & 44,0 & 20 & 55,6 \\
\hline I/ | $\mid / N C$ & 16 & 8,0 & 11 & 22,0 & 9 & 25,0 \\
\hline$|1 /||| / N C$ & 9 & 4,5 & 6 & 12,0 & 6 & 16.7 \\
\hline$|/||/||| / N C$ & 4 & 2.0 & 4 & 8,0 & 4 & 11,1 \\
\hline Não Tipável & 35 & 17.4 & 19 & 38,0 & 16 & 44,4 \\
\hline
\end{tabular}

\footnotetext{
NC $=$ Não Classificado

- $\quad$ para 201 cepas

* $\quad$ para 50 amostras positivas

-. = para 36 propriedades leiteiras com amostras positivas
} 
Staphricaccus aurous em leite cru. I. Contegem, verificação da enterotoxigenicidede ...

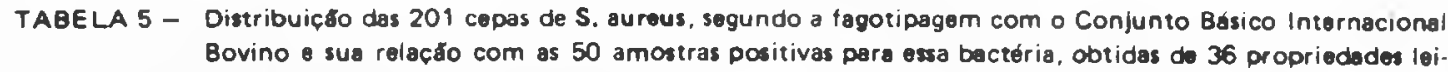
teiras Pirassunungs, SP, 1981.

\begin{tabular}{|c|c|c|c|c|c|c|}
\hline \multirow[t]{2}{*}{$\begin{array}{l}\text { S. aurous correspondentes aos } \\
\text { Grupos de fagos }\end{array}$} & \multicolumn{2}{|c|}{$\begin{array}{l}\text { Cepas de } \\
\text { S. aureus. }\end{array}$} & \multicolumn{2}{|c|}{$\begin{array}{l}\text { Amostras } \\
\text { de leite }{ }^{\circ}\end{array}$} & \multicolumn{2}{|c|}{$\begin{array}{l}\text { Propriedades } \\
\text { leiteiras } \cdots\end{array}$} \\
\hline & $N$ & $\%$ & $N$ & $\%$ & $\mathbf{N}$ & $\%$ \\
\hline 1 & 13 & 6.5 & 6 & 12.0 & 6 & 16.7 \\
\hline 11 & 3 & 1.5 & 3 & 6.0 & 2 & 5,6 \\
\hline 111 & 34 & 16,9 & 18 & 36,0 & 17 & 47.2 \\
\hline IV & 35 & 17,4 & 14 & 28,0 & 13 & 36,1 \\
\hline$M$ & 6 & 3,0 & 6 & 12.0 & 5 & 13,9 \\
\hline$|/ 11|$ & 4 & 2,0 & 3 & 6.0 & 3 & 8,3 \\
\hline I/IV & 1 & 0.5 & 1 & 2.0 & 1 & 2.8 \\
\hline$I / M$ & 2 & 1,0 & 1 & 2.0 & 1 & 2,8 \\
\hline $11 / 111$ & 5 & 2.5 & 4 & 8.0 & 4 & 11.1 \\
\hline $1 \mathrm{IIIV}$ & 4 & 2.0 & 4 & 8.0 & 4 & 11,1 \\
\hline $11 / M$ & 2 & 1.0 & 2 & 4.0 & 1 & 2.8 \\
\hline III/IV & 25 & 12.4 & 15 & 30.0 & 14 & 38.9 \\
\hline $111 / M$ & 5 & 2,5 & 5 & 10,0 & 5 & 13,9 \\
\hline$I V / M$ & 7 & 3,5 & 6 & 12.0 & 6 & 16.7 \\
\hline $1 / I I I / I V$ & 4 & 2.0 & 2 & 4.0 & 2 & 5,6 \\
\hline $1 / 11 / / M$ & 3 & 1.5 & 3 & 6.0 & 3 & 8,3 \\
\hline $11 / 111 / I V$ & 7 & 3.5 & 6 & 12,0 & 6 & 16.7 \\
\hline$I I / I V / M$ & 6 & 3,0 & 6 & 12.0 & 5 & 13,9 \\
\hline$I I I / I V / M$ & 6 & 3,0 & 6 & 12,0 & 6 & 16.7 \\
\hline $11 / \| 11 / M$ & 3 & 1,5 & 3 & 6,0 & 3 & 8,3 \\
\hline$\|/\| I / I V / M$ & 2 & 1.0 & 2 & 4.0 & 2 & 5,6 \\
\hline I/II/III/IV/M & 1 & 0,5 & 1 & 2,0 & 1 & 2,8 \\
\hline NÉO Tipstvel & 23 & 11,4 & 13 & 26.0 & 12 & 33,3 \\
\hline
\end{tabular}

M - Miscelánea

- - para 201 cepas

- - para 50 amostras positivas

... - para 36 propriedades loiteiras com amostras positivas 
01-AHMEO, A.A.; TERPLAN, G; SIMON, E. Enterotoxigenicity of staphylococcal strains isolated from milk and doiry products. Arch Lebensmitt. Hyg., 29:212-214, 1978.

O2-AMOERSON, P.H.R. \& STONE, D.M. Staphylococcal food poisoning associated with spray-dried milk. J. Hyg., London, 53:387-397, 1955.

03-AMGELOTI, R. Staphilococcal intoxications. In: RIEMAN, H., ed. Foadborne infections and intoxications. New York, Academic Press, 1969. p. 359-393.

O4-ARM!JO, R.; HENDERSON, D.A.; TIMOTHEE, R.; ROBINSON, H.B. Food poisoning outbreaks associated with spraydried milk: an epidemiologic study. Amer. J. publ. Hith., 47:1093-1100, 1957.

05-BAIRD-PARKER, A.C. An improved diagnostic and seletive medium for isolating coagulase positive staphylococci. J. appl. Bact., 25:12-19, 1962.

Q6-BAIRO-PARKER, A.C. Methods for classifying staphylococci and mierococci. In: GIBBS, B.M. \& SKINMER, F.A., eds. Identification methods for microbiologiss. London, Academic Press, 1966. p. 5964.

07-BAIRD-PARKER, A.C. Gram positive cocci. In: BUCHANAN, E.E. \& GIBBONS, N.E. Bergey's manual of determinatne bacteriology. 8. ed. Baltimore, Williams \& Hilkins, 1974. p. $478-528$.

08-BERGOOLL, M.S. Enterotoxin detection. In: HOBBS, B.C. \& CHRISTIAN, J.H.B., eds. The microbiological safery of food. New York, Acodemic Press, 1973. p. 287-292.

09-BLAIR, J.E. \& WILLINMS, R.E.0. Phage typing of staphylococci. Bull. Whd Hilh Org., 24:771-784, 1961.

10-CABRAL, T.M.A.; IARIA, S.T.; LIMA, A.H.O. Bactérias mesofilos coliformes totais e fecais e Staphilococcus aureus en queijo "coalho" comercializado en João Pessoa, Paraíba. In: CONGRESSO Latino MMERICANO DE MICROBIOLOGIA, 9.; CONGRESSO BRASILEIRO DE MICROBIOLOGIA, 12., São Paulo, 1983. Programa. Resumos. São Paulo, Associação Latino Americana de Micrabiologia/ Sociedade Brasileira de Microbiologia, 1983. p. 157.
11-CASMAN, E.P. \& BENMETT, R.W. Detection of staphylococcal enterotoxin in food. Appl. Microbiol., 13:181-189, 1965 .

12-CASMAN, E.P.; BENMETT, R.H.; DORSEY, A.E.; ISSAY, J.A. Identification of a fourth staphylococeal enterotoxin. Enterotoxin D. J. Bacl., 94:1875-1882, 1967.

13-CERQUEIRA-CAMPOS, M.L. \& IARIA, S.T. Contagem de Staphylococcus aureus en carne moida e verificaçāo da produçāo de enterotoxina pelas cepas isoladas. In: CONGRESSO latino nMericano de microbiologia, 9.; CONGRESSO BRASILEIRO OE MICROBIOLOGIA, 12., Sāo Paulo, 1983. Programa. Resumos. São Paulo, Associação Latino Americana de Microbiologia/ Sociedade Brasileira de Microbiologia, 1983. p. 146.

14-COMITE MIXTO FAO/OMS DE EXPERTOS EN HIGIENE DE LA LECHE. Ginebra, 1969. Tercer informe. Ginebra, Organización Mundial de la Salud, 1971. (Informes téenicos, 453)

15-CORLETT, D.A. \& BROWN, M.H. PH and acidity. in: INTERMATIONAL COMMISSION ON MICROBIOLOGICAL SPECIFICATION FOR FOOOS. Microbial ecology of foods: factor affecting life and death of microorganisms. New York. Academic Press, 1980. v. 1, p. 92-111.

16-DACK, G.M. Food poisoning. 3. ed. Chicago, University of Chicago Press, 1964. p. 109-158.

17-DAVIDSON, 1. A set of bateriophages for typing bovine staphylococci. Res, ver. Sci., 2:396-407, 1961.

18-DELAZARI, I. \& LEITIO, M.F.F. Staphylococcus auseus enteropatogènico em macarrão. Colet. Ins. Tecnol. Alim, $7: 485-497,1976$.

19-DONMELY, C.B. LESLIE, J.E.; BLACK, L.A., LEWIS, K.H. Serological identification of enterotoxigenic staphylococci from cheese. Appl. Microbiol., 15:13821387, 1967.

20-EVANS, J.B. Studies of staphylococci with special reference to the coagulase-positive types. J. Bach, $55: 793-800,1948$. 
Staphvlococcus aureus em leite cru. I. Contagem, verificaçāo de enterotoxigenicidade...

21-EVANS, J.8.; BUETTNER, L.G.; NIVEN JUNIOR, C.F. Evaluation of the coagulase test in the study of staphylococci associated with food poisoning. I. Bacl, 60:481-484, 1950 .

22-FERnamdeZ, G.S. Microflora estafilocica de leche natural. An. Fac. Va. Leon, 12:11-166, 1966.

23-FRAZIER, U.C. \& VESTHOFF, O.C. Foad microbiology. 3. ed. New York, McGraw-Hill, 1978. p. $432-438$.

24-FURLANETTO, S.M.P.; MADER FILHO, A.; HILSON, D.; SCHOCKEN-ITURRINO, R.P. Staphylococcus aureus enterotoxigenicos isolados a partir de leite de vacas mast ticas. Re:. Microbiol., 18:138-143, 1987.

25-GARCIA, M.L.; MORENO, B.; BERGDOLL, M.S. Characterization of staphylococci isolated from mestitic cous in Spain. Appl. enironm. Microbiol, $39: 548 \cdot 553,1980$.

26-GHOSH, S.S. \& LAXMIMARAYAMA, H. Enterotoxigenic staphilococci in milk and milk products. Indian $J$ anum. Sci, 42:492-498, 1972.

27-GHOSK, S.S. \& LAXMIMARAYAMA, H. Incidence and distribution of staphylococci in milk and milk products. Indian J. anim. Hllh 13:117-120. 1974.

28-GILBERT, R.J. Staphylococcal food poisoning and botul ism. Postgrad. med. J., 50:603-611, 1974.

29-GILBERT, R.J. \& HIENEKE, A.A. Staphylococcal food poisoning with special reference to the detection of enterotoxin in food. In: HOOBS, B.C. \& CHRISTIAN, J.H.B., eds. The microbiological safery of food. New York, Academic Press, 1973. p. 273-285.

30-GOMEZ, R.I.; ROMERO, M.R.; PARRILLA, M.C.; GONZALEZPACHECO, M. Incidencia de $S$. aureus en quesos a nivel de mercado en el Distrito federal. Rev. las.amer. Microbiol, 21:67-68, 1979.

31-HIROOKA, E.Y. \& MULER, E.E. I solamento, caracterizacão e enterotoxigenicidade de cepas de Slaphylococcus aureus isolados de produtos cárneos comercializados em Lonór ina, Paraná. Ci Tecnol. Alim., $2: 123-133,1982$.

32-HOOBS, B.C. GILBERT, R.J. Food poisoning and food hygiene. 4. ed. London, Edward Arnold, 1978. p. 366.
33-IARIA,S.T. Slaphylococcus aureus enterotoxigènico en doces cremosos vendidos em padarias confeitarias do Município de Sāo Paulo, Brasil. Rev. Saúde públ, São Paulo, 15:321-337, 1981.

34-INTERNATIONAL COMMISSION ON MICROBIOLOGICAL SPECIFICATIONS FOR FOOOS. Microorganisms in foods. 1. Their significance and methods of enumeration. 2. ed. Toronto, University of Toronto Press, 1978.

35-JAY, J.M. Toxinfecciones alimenticias causadas por cocos gram-positivos. In: .... Microbiologia moderna de los alimentos. Zaragoza, Acribia, 1973. p. 190-209.

36-KATO, E. \& XUME, T. Enterotoxigenicity of bovine staphylococci isolated from California Mastitis Test-positive milk in Japan. Jap. J. vet. Res., 28: $75-85$, 1980.

37-KUMAR, A. \& GUPTA, R.S. Enterotoxigenic SLaphylococcus aureus isolated from foods and human sources. Indian vet. J., $60: 595-598,1983$.

38-LACHICA, R.V.F.; GENIGEORGIS, C.: HOEPRICH, P.D. Metachromatic agardiffusion methods for detecting nuclease staphylococcal activity. Appl. Microbiol., $21: 585-587,1971$.

39-LOMBAI, G.; JANOSI, L.; KATOMA, F.; MAJOR, P., MILCK, H.; ORMAY, L.; TAKACS, J. Properties and $\$ 000$ hygiene significance on strains of Staphylococcus aurews isolated from udders of cows. Anch. Lebensmia.Hyg., $31: 206 \cdot 209,1980$.

40-MARKAM, N.P. \& MARKHAM, J.G. Staphylococci in main and animal. Distribution and characteristics of strains. J. comp. Path., 76:49-56, 1966.

41-MORRISON, S.M.; FAIR, J.F.; KENNEDY, K.K. Slaphylacoccus aureus in domestic animals. Publ. Hith Rep., Washington, 76:673-677, 1961 .

42-HADER FILHO, A.; ROSSI JUNIOR, O.D.; SCHOCKENITURRINO, R.P. Pesquisa de Slapylococcus aureus enterotoxigenicos en leite de vacas com mastite subclínica. Rev. Mucrobwol, 19:369-373, 1988.

43-nakagaha, M. studies on bacteriophage typing of a staphylococci isolated from bovine milk. 111 . Typing by means of a new phage set. Jap. J. ver. Res., $8: 331-342,1960$.

Rev. Fac. Med. Vet. Zootec. Univ. S. Paulo, 26/2/:187-198, 1989. 
44-OLSOW, J.C.; CASMAN, E.P.; 8AER, E.F.; STONE, J.E. Enterotoxigenicity of Staphylococcus aureus cultures isolated from acute cases of bovine mastitis. Appl. Microbiol., 20:605-607, 1970.

45-PETERSON, A.C.; BLACK, J.J.; GUNDERSON, M.F. staphylococei in competition. 1. Growth of naturally ocurring mixed populatins in preecooked frozen foods during defrost. Appl. Microbiol., 10:16-22, 1962.

46-RAHMAN, H. B BAXI, K.K. Studies on staphylococcal mastit is in bovine. Indian vet. $J_{.} 60: 865-869,1983$.

47-RUDGE, A.C. Aspecios microbiológicos e sanitários de linguiça lipo frescal: anólise de comaminaçäo por Staphilacaccus aureus e Clostridium perfringens. Botucatu, 1980. /Tese de Livredocencia - Faculdade de Medicina Veterinária e Zootecnia da UNESP/

48-SCHOCKEN-I TURRINO, R.P.; NADER FILHO, A.; FURLANETTO, S.M.P.: ROSSI JUNIOR, O.D. Pesquisa de Staphilococcus aureus enterotoxigènicos en amostras de leite de vacas mastíticas. Ars vet., 2:69-74, 1986.

49-SETO, J.T. \& WILSON, J.B. Bacteriophage typing of microcossi of bovine origin. Amer. J. vet. Res., $19: 241,246,1958$.

50-SIles VILLARROEL, M. Conaribuiçáo ao esiudo de venenos de serpentes do gênero Bothrops ( $B$ jararaca, $B$. alternatus, $B$. Insularis, B. jararacassu, B. athrox e B. cotiaral. São Paulo, 1972. /Tese de doutoramento - Instituto de Ciências 8 ionedicas da USP/
51-SIMKOVICOVA, M. \& GILBERT, R.J. Serological detection of enterotoxin from food-poisoning strains of Staphylococcus aureus. J. med. Microbiol., 4:19-30, 1971.

52-SOLE-VERNIN, C. Fagotipagem de Staphilocaccus aureus. Rev. bras. Oriop., /1:31-34, 1976.

53-SUBCOMMITTEE ON TAXONOMY OF STAPHYLOCOCCI AND MICROCOCCl. Minutes of first meeting 1964. Ins. Bull. bact. Nomencl, 15:107-108, 1965.

54-TAKESHIGE, K.; hATAMABE, K.; IGARASHI, H.; SHINGAKI, M.: TERAYAMA, T. Detection of Staphylococcus aureus in bovine mastitis and some characteristics with special reference to enterotoxin producibility and coogulase types of isolates. Jap. J. vet. Sci., 45:355. 362,1983 .

55-TROLLER, J.A. \& CHRISTIAN, J.H.8. Water activity and food. New York, Academic Press, 1978.

56-WIENEKE, A.A. Enterotoxin production by strains of Staphylococcus aureus isolated from foods ard human beings. J. Hyg. , London, 73:255-262, 1974.

57-WILLIAMS, R.E.0.; RIPPON, J.E.; DOUSETT, L.H. Bacteriophage typing of strains of Staphilococcus aureus from various sources. Lancet; 264:510-514, 1953.

58-HILSON, D. Pesquisa de Staphylococcus aureus em leite a ser pasteurizado. Rev. Saúde públ., São Paulo, $11: 1-11$, 1977.

59-2ELANTE, F. Conoribuiçào para o estudo de Staphilococcus isolados de canais radiculares. São Poulo, 1974. /Tese de Livredocència - Instituto de Cièncias Biomédicas da USP/ 